
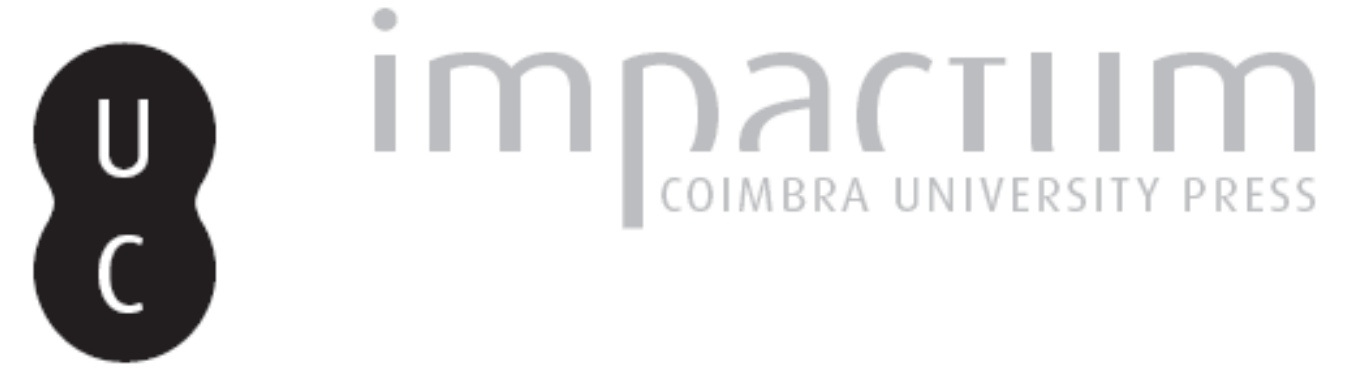

\title{
[Recensão a] La letteratura portoghese. I testi e le idee, a cura di Roberto Vecchi; Vincenzo Russo
}
Autor(es):
Ragusa, Andrea

Publicado por: Imprensa da Universidade de Coimbra

URL persistente:

URI:http://hdl.handle.net/10316.2/45648

DOI:

DOI:https://doi.org/10.14195/0870-8584_13_15

Accessed : $\quad$ 26-Apr-2023 07:43:15

A navegação consulta e descarregamento dos títulos inseridos nas Bibliotecas Digitais UC Digitalis, UC Pombalina e UC Impactum, pressupõem a aceitação plena e sem reservas dos Termos e Condições de Uso destas Bibliotecas Digitais, disponíveis em https://digitalis.uc.pt/pt-pt/termos.

Conforme exposto nos referidos Termos e Condições de Uso, o descarregamento de títulos de acesso restrito requer uma licença válida de autorização devendo o utilizador aceder ao(s) documento(s) a partir de um endereço de IP da instituição detentora da supramencionada licença.

Ao utilizador é apenas permitido o descarregamento para uso pessoal, pelo que o emprego do(s) título(s) descarregado(s) para outro fim, designadamente comercial, carece de autorização do respetivo autor ou editor da obra.

Na medida em que todas as obras da UC Digitalis se encontram protegidas pelo Código do Direito de Autor e Direitos Conexos e demais legislação aplicável, toda a cópia, parcial ou total, deste documento, nos casos em que é legalmente admitida, deverá conter ou fazer-se acompanhar por este aviso.

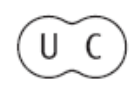




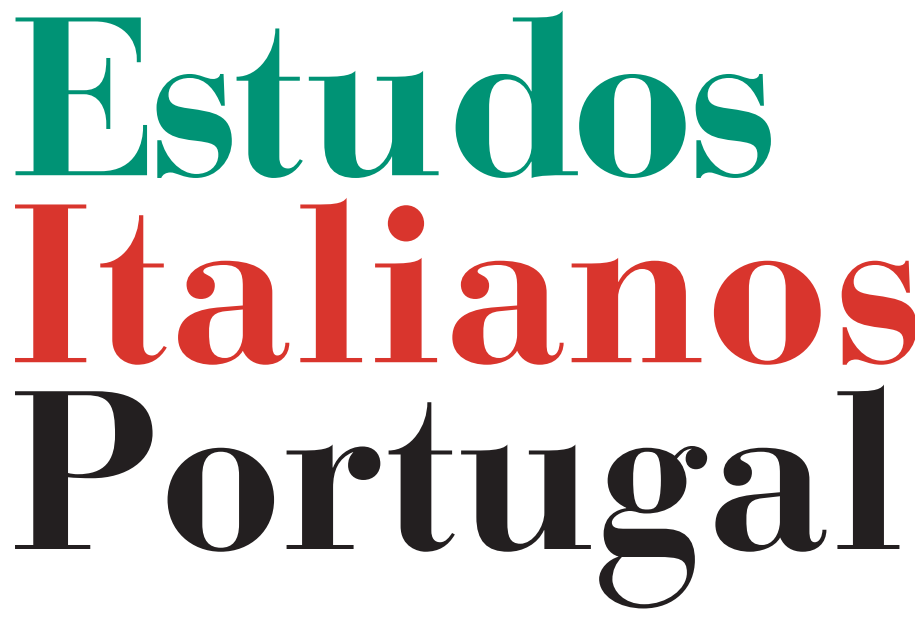

Instituto

Italiano

de Cultura

de Lisboa

Nova Série

$\mathrm{N}^{\mathbf{0}} 13$

2018 
seria, para tal oriental masoquista, um gozo!).

Apesar de ter havido, no mesmo período, europeus que elogiavam a civilização do Islão e o seu Profeta - entre eles Friedrich Nietzsche e Antero de Quental - não se estranha que, dadas as circunstâncias históricas e culturais, De Amicis descrevesse o Islão e o chamado Oriente com um olhar ideológico e de preconceito, tal como tinha feito no seu anterior diário de viagem dedicado a Marrocos (Marocco, 1873). A este respeito repare-se que, segundo Umberto Eco, autor do prefácio de Constantinopla, a "peregrinação" cultural de De Amicis ao "Santuário do Diferente" é tornada "patética" pelas próprias matrizes histórico-culturais envolvidas.

Por todas estas razōes, destacamos o valor científico da publicação em Portugal de Constantinopla, sobretudo pelas possibilidades críticas que a sua leitura oferece, para o estudo - com um olhar atento aos desafios da contemporaneidade das condições e dos contextos geopolíticos, históricos e culturais da sua composição, publicação, receção e reedição. FABRiZio BosCaGlia

La letteratura portoghese. I testi e le idee, a cura di Roberto Vec- chi; Vincenzo Russo, Firenze, Le Monnier, 2017, 642 pp.

Qualsiasi tentativo di ricostruire la storiografia letteraria portoghese implica inevitabilmente il confronto con un intricato labirinto che assorbe dal passato mitico, più ancora che da quello storico, il proprio sostrato essenziale. Intorno a questa fondamentale considerazione si articola l'importante volume antologico curato da Roberto Vecchi e Vincenzo Russo, dedicato - non a caso - a Eduardo Lourenço, a cui peraltro si deve l'illuminante (e ormai storica) riflessione intorno al concetto di "labirinto della saudade", topos critico tramite cui, analizzando i processi dell'immaginazione e dell'arte, si tenta di spiegare e di rendere coerente un "complesso storico di incompiutezza". Lo stesso Lourenço, in un recente articolo pubblicato sul Jornal de Letras ( $\mathrm{n}^{\circ} 258$, luglio 2018), invitava a riflettere sulla natura e sulla qualità attuali della presenza letteraria portoghese al di fuori dei confini nazionali e sulle relazioni tra Stato e cultura (quindi su maggiore o minore "cultura della rappresentazione di Stato" nel contesto "ricevente") che si trova alla base di tale presenza.

La letteratura portoghese. I testi e le idee si pone - come affermano gli stessi curatori - come "cerniera" 
verso altre opere congeneri già esistenti, valorizzando la ricca tradizione della lusitanistica italiana che affonda le sue radici moderne nel tardo Ottocento - con "lusofili" come Cannizzaro, Peragallo, Padula, Teza - e che acquisisce, dalla seconda metà del XX secolo (salvo precedenti casi sporadici, come quello di Guido Battelli), la sistematicità scientifica e i connotati accademici che caratterizzano la recente storiografia della letteratura portoghese: dai "pionieri" Francesco Piccolo (1970) e Giuseppe Carlo Rossi (1975), ai più recenti contributi di Luciana Stegagno Picchio (2001), Giovanni Ricciardi e Roberto Barchiesi (1998), Giulia Lanciani (1999 e 2015) e Valeria Tocco (2011).

Dal punto di vista del supporto strettamente critico, i saggi di Alfredo Bosi ("Colonia, culto e cultura”), Margarida Calafate Ribeiro (su impero e guerra coloniale), José Gil (su Salazar) e dello stesso Eduardo Lourenço ("Portogallo come destino"), forniscono le coordinate essenziali per muoversi all'interno del volume, tra "fictum e factum", quindi tra testo e contesto, mitologia e storia, apogeo e decadenza. Il percorso attraverso $\mathrm{i}$ testi (in lingua originale, con traduzione a fronte o in calce) inizia con alcuni capitoli dell' Arte de Trovar, vero e proprio manuale "pra- tico" della composizione poetica, seguiti da una selezione di cantigas medievali, tra cui emerge la posizione di D. Dinis, particolarmente emblematica nell'ottica della specificità del caso letterario portoghese - già dalle origini - in relazione a elementi culturali o artistici provenienti dall'esterno: Proençaes soem mui bem trobar (I provenzali sogliono molto bene poetare), prima poesia raccolta nel volume, può essere letta, in effetti, come una sorta di "manifesto", in cui, pur non venendo mai negato il modello provenzale, si rivendica tuttavia un'autonomia rispetto agli stilemi che caratterizzano quel particolare genere di creazione poetica. Molto rilevante è anche la scelta dei testi relativi alla vita cortigiana e al Cancioneiro geral di Garcia de Resende, all'epoca rinascimentale (Gil Vicente e Bernardim Ribeiro), alla cosiddetta medida nova e ai "due umanesimi" (Sá de Miranda, João de Barros, António Ferreira, Camóes), oltre alla storia della lingua portoghese e alla sua relazione con l'impero (Fernão de Oliveira e João de Barros).

Il concetto culturale di impero, sia in chiave storica che mitica, si sviluppa, peraltro, in maniera trasversale lungo tutte le sezioni del volume: a cominciare dai resoconti di viaggio (Pêro Vaz de Caminha, Fernão Mendes Pinto, Pêro Magal- 
hães de Gândavo), alla storiografia (da Zurara a D. Duarte, da Gaspar Correia a Damião de Gois), fino all'epopea letteraria (Os Lusíadas) e alla costruzione teorica di una patria mitica (Padre António Vieira e Fernão Álvares do Oriente). $\mathrm{La}$ selezione consente anche $\mathrm{di}$ ricostruire l'esaltazione dei "concetti" che - sull'onda del gongorismo, prima, e dell'aristotelismo di Tesauro, poi - caratterizzano il Barocco portoghese, da Leitão Ferreira a Francisco Manuel de Melo, da Violante do Céu a Jerónimo Baía (gli ultimi tre anch'essi antologizzati), oltre alle due sezioni dedicate all'Arcadia lusitana (testi di Correia Garção, Tomás António Gonzaga, Cláudio Manuel da Costa) e alle "nuove arcadie" tra Sette e Ottocento (Marquesa de Alorna, Bocage, Filinto Elísio).

La "rimitologizzazione" della Storia e della patria (dal Camóes di Garrett alle Lendas e Narrativas di Herculano) e la generazione "ultraromantica" (su tutti Camilo Castelo Branco) aprono il terreno alla prima, grande "rivoluzione" culturale moderna, quella operata su vari fronti della cultura e del pensiero sociopolitico dalla Geração de 70 , alla quale è dedicata un'ampia sezione di testi (Antero poeta e Antero pensatore, Eça de Queirós, Oliveira Martins). La stessa attenzione è riservata alla letteratura di fine
Ottocento (tra cui $O$ sentimento de um ocidental di Cesário Verde, ma anche Eugénio de Castro, Nobre) e del primo Novecento (Pessanha, Pascoaes, Raul Brandão, Florbela), essenziali per comprendere quegli "spettri della modernità" che si riflettono nell'avvento di Orpheu e dei suoi protagonisti (su tutti, naturalmente, Pessoa, Sá-Carneiro e Almada, ai quali sono dedicate due intere sezioni), poi canonizzati e "rivisitati" dalla "contro-rivoluzione" di Presença, qui rappresentata dai testi di José Régio (critica), Miguel Torga e Adolfo Casais Monteiro (poesia).

Alle parti dedicate al neorealismo (i gaibéus di Alves Redol, i romanzi di Carlos de Oliveira), al surrealismo (Cesariny, O'Neill) e alle "singolarità novecentesche" di Aquilino, Agustina, Nemésio e Vergílio Ferreira, seguono due parti dedicate alla letteratura dell'epoca salazarista e coloniale (Jorge de Sena, Ruy Belo, Ramos Rosa, Sophia, Fernando Assis Pacheco, Nuno Bragança, solo per citarne alcuni), fino alle monumentali opere di José Saramago e António Lobo Antunes, delle quali viene fornita una nutrita selezione.

Il volume si chiude con una serie di testi che evidenziano alcune tendenze costanti del pensiero e della letteratura portoghese contemporanei: dal punto di vista 
critico, l'"iper-identità" e l'idea di "periferia", aspetti evidenziati da Bonaventura de Sousa Santos, ma anche il concetto di "non-decolonizzazione" sostenuto da Eduardo Lourenço; dal punto di vista prettamente letterario, il "post-memoria” di Isabela Figueiredo e Dulce Maria Cardoso, il pós-tudo delle opere più recenti di Lídia Jorge $(O s$ memoráveis) e gli itinerari "malinconici” di Gonçalo M. Tavares in Uma viagem à Índia.

Il volume pubblicato da Le Monnier ha l'importante funzione di ricucire i percorsi della lusitanistica con una preziosa raccolta di testi che permette di arricchire l'analisi critica con l'"archivio" che l'ha generata, attraverso una periodizzazione storica non rigida, ma adeguata e funzionale a determinate "costellazioni concettuali": non, chiaramente, una paradossale proposta "astorica" di periodizzazione, ma una storiografia che si confronta e dialoga con la costituzione mitica di uno specifico spazio letterario. Andrea Ragusa

\section{Paola D'Agostino, Tancredi il} napoletano, Livorno, Vittoria Iguazu, 2018, 109 pp.

A criação do contexto desta narrativa parte do cap. II do famoso romance de Eça de Queiroz, Os Maias, em que se narra a chegada imprevista de um italiano a Lisboa e que se dizia «sobrinho dos príncipes de Sória, e vinha fugido de Nápoles, onde conspirara contra os Bourbons e fora condenado à morte». Este personagem, a quem Eça chama Tancredo, ou simplesmente "o napolitano", surge na obra queiroziana como uma espécie de meteoro fugaz mas com uma função determinante no desencadear da tragédia: como uma fatalidade, é com ele que Maria de Monforte foge com a filha Maria (a futrura Maria Eduarda), o que conduz Pedro da Maia ao suicídio. Paola D’Agostino considera, não sem razão, que certos personagens, apenas esboçados como neste caso, merecem ser subtraídos ao esquecimento, reclamam vida, pelo que nos apresenta esta "parabola di Tancredi, ovvero la storia possibile di un personaggio letterario che scalcia per chiedere giustizia ai propri lettori» ("premessa", p. 9).

Escusado será dizer que esta narrativa estabelece uma forte relação de intertextualidade com a obra queiroziana, influente na criação do contexto e pré-texto a partir dos quais se amplifica agora a acção: a fuga dos dois amantes com passagem por Veneza até se estabelecerem em Viena, mas com a oportunidade de esclarecer o passado histórico de Tancredi, filho da revolução que na «città del sole» era 